\title{
Factors associated with treatment default by tuberculosis patients in Fez, Morocco
}

K. Slama, ${ }^{1}$ N. Tachfouti, ${ }^{2}$ M. Obtel ${ }^{2}$ and C. Nejjari ${ }^{2}$

$$
\text { كاتيا سلامة، نبيل تشفوتي، بمدولين المعالجة لمرضى أوبتيل، شكيب نجار في فاس، المغرب }
$$

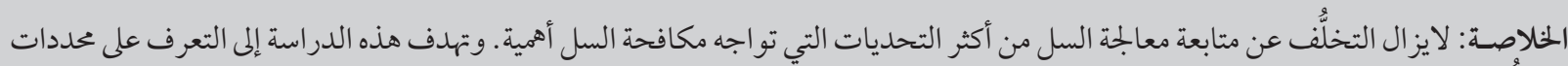

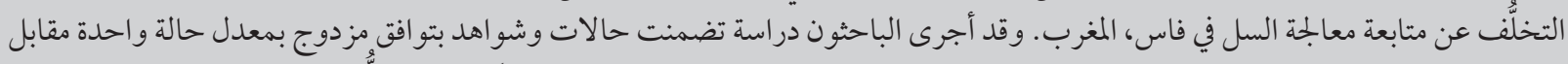

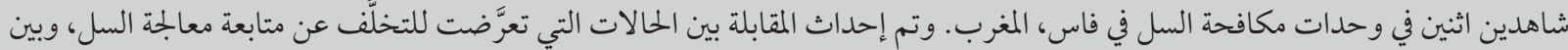



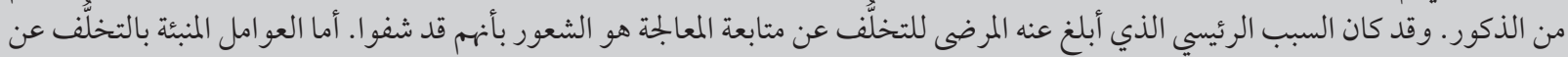

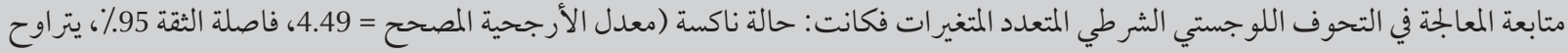



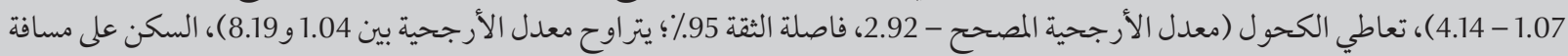

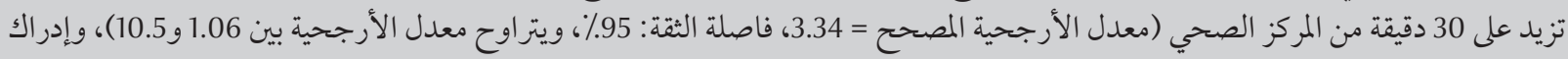



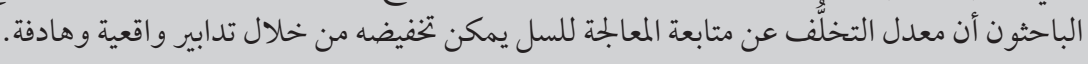

ABSTRACT Interruption in tuberculosis (TB) treatment still remains the most important challenge for control of the disease. This study aimed to identify the determinants of TB treatment default in Fez, Morocco. A 1:2 pairmatched case-control study was carried out in the TB control units in Fez. Cases were defaulters to TB treatment and were matched by age and sex to non-defaulters (controls). Of the 320 patients (108 defaulters, 212 controls), $80.6 \%$ were male. The main reason for defaulting reported by patients was the sensation of being cured. Predictive factors for treatment default in the multivariate conditional logistic regression analysis, were: relapsed case (adjusted $\mathrm{OR}=4.49 ; 95 \% \mathrm{Cl}: 1.87-10.8)$, current smoking ( $\mathrm{aOR}=2.10 ; 95 \% \mathrm{Cl}: 1.07-4.14)$, alcohol use (aOR = 2.92; 95\% Cl: 1.04-8.19), being more than 30 minutes away from the health centre $(\mathrm{aOR}=3.34 ; 95 \% \mathrm{Cl}: 1.06-10.5)$ and perception of having received insufficient explanation about the disease $(\mathrm{aOR}=2.87 ; 95 \% \mathrm{Cl}: 1.53-5.36)$. The rate of defaulting in Fez can be lowered through targeted and realistic measures.

\section{Facteurs associés à l'abandon du traitement chez des patients atteints de tuberculose à Fès (Maroc)}

RÉSUMÉ L'interruption du traitement de la tuberculose reste encore le défi le plus important pour la lutte contre cette maladie. La présente étude vise à identifier les déterminants de l'abandon du traitement de la tuberculose à Fès (Maroc). Une étude cas-témoin appariés avec un rapport de 1 pour 2 a été menée au sein des unités de lutte contre la tuberculose à Fès. Les cas concernaient des patients ayant abandonné le traitement contre la tuberculose. Ils ont été appariés selon l'âge et le sexe à des témoins ayant achevé leur traitement. Sur un total de 320 patients (108 abandons, 212 témoins), 80,6 \% étaient de sexe masculin. La principale raison citée par les patients ayant abandonné était la sensation d'être guéri. Les facteurs prédictifs d'un abandon de traitement dans une analysederégressionlogistiqueconditionnelle multivariéeétaientlessuivants: unerechute(ORajusté=4,49;ICà95\%: 1,87-10,8), laconsommationdetabac(ORajusté=2,10; ICà95\%:1,07-4,14), laconsommationd'alcool(ORajusté=2,92; IC à $95 \%$ : 1,04-8,19), l'éloignement du lieu de résidence de plus de 30 minutes du centre de santé (OR ajusté =3,34 ; IC à $95 \%: 1,06-10,5)$ et l'impression d'avoir reçu des explications insuffisantes sur la maladie (OR ajusté = 2,87 ; IC à $95 \%$ : 1,53-5,36). Le taux d'abandon à Fès peut être réduit au moyen de mesures ciblées et réalistes. 


\section{Introduction}

Tuberculosis (TB) remains a major public health problem in the world [1]. According to World Health Organization (WHO) estimates, approximately 9.4 million new cases were reported in 2009. A contagious person left untreated will infect up to 15 people every year and so treatment of active pulmonary TB patients remains the most effective strategy to stop the spread of the disease [2]. However, interruption in TB treatment still remains the major barrier to control of the disease.

In Morocco, TB is a highly prevalent infection, affecting more than 26000 people in 2009, with an incidence of approximately 82 new cases per 100000 population [3]. The Moroccan government is committed to fighting TB, strengthened by the adoption of the national strategic plan 2006-2015, which aims to enhance the therapeutic delivery system to $\mathrm{TB}$ patients and accelerate the reduction in incidence of smear-positive cases (microscopy-positive pulmonary TB). With annual rates of TB detection over $80 \%$ and therapeutic success over $85 \%$ [4]. Morocco is one of the few middleincome countries achieving the millennium development goals (MDGs) and Stop TB Partnership targets of 70\% case detection rate and $85 \%$ success rate for treatment,

In Morocco, TB clinical care is provided at a public health centre and TB treatment is delivered at local dispensaries following the DOTS strategy. Despite the fact that TB treatment is free of charge, a high proportion of new smear-positive cases voluntarily interrupt their treatment before the end. Default from treatment is detrimental, not only to the patient, who will not recover [5-7], but also at the community level, with the emergence of bacteria strains with acquired resistance to common TB antibiotics [8-11]. Default from treatment is a major obstacle in the fight against TB in Morocco, and was estimated at around $10 \%$ in 2009 [2]. Adherence to the long course of TB treatment is a complex, dynamic phenomenon with a wide range of factors impacting on patients' treatment-taking behaviour. So far, there are little data on the determinants of TB treatment default in Morocco or reasons for defaulting reported by patients.

The main objective of this study was to identify the determinants of $\mathrm{TB}$ treatment default in the region of Fez, Morocco. The characteristics found to be associated with default among $\mathrm{TB}$ patients as well as determination of structural barriers may help control programmes to improve compliance and work more effectively towards the aim of MDG 6 to eliminate TB as a public health problem by 2050 .

\section{Methods}

\section{Setting and design}

The research was designed as a casecontrol study conducted in 10 different TB control units (TCUs), from a total of 28 TCUs in the town of Fez. The TCUs were selected based on caseload, accessibility and nurses' willingness to participate. TCUs were located in low-, medium- and high-income neighbourhoods.

\section{Study population}

Eligible patients for the study included TB patients (new cases or relapsed) who were enrolled in treatment for TB between 1 January 2009 and 31 December 2010. Patients were identified from the TCU registers and contacted to answer a questionnaire. Participants were male or female, aged 15 years or older, had been diagnosed with active TB (defined according to WHO criteria) and had started TB treatment according to international guidelines [12]. All TB treatment defaulters in 2009 and 2010 identified in the participating TCUs were selected for the study. A total of 16 patients refused to participate, among whom 12 were defaulters. In total, $120 \mathrm{~TB}$ treatment defaulters were selected for the study. Cases and controls were matched by sex and age, and for each case of default 2 non-defaulters were selected. Patients who refused to take part in the study were excluded. A defaulter (case) was defined as a TB patient who interrupted treatment for 2 months or longer before the end of the treatment period, according to the WHO definition [12]. Anondefaulter (control) was defined as a TB patient diagnosed in the same time period, from the same TCUs, following the same treatment protocol, but who completed the whole treatment regimen. A total of 320 patients (108 defaulters and 212 non-defaulters) entered the study.

\section{Data collection}

Ananonymousquestionnaire was developed and pre-tested. Adjustments were made after assembling a focus group of all nurses participating in the study. The nurses were staff members of the TCUs and were responsible for actively searching for cases and controls to collect the data. Participants were interviewed in the TCUs. The questionnaires focused on factors that might be associated with default: sociodemographic factors (sex and age, marital status, employment status, educational level, housing area and conditions, monthly earnings), medical information (new TB case or relapsed, pulmonary or extrapulmonary location), health insurance coverage, distance to TCU, addictive behaviours (tobacco and alcohol), side-effects to treatment, explanations received about the disease, knowledge and attitudes related to $\mathrm{TB}$ and subjective reasons for defaulting.

The purpose of the study was explained in detail to each patient agreeing to participate in the study, and oral informed consent was obtained prior to interviews. The anonymity of questionnaires was strictly respected. 


\section{Data management and statistical analysis}

The data were entered and analysed at the epidemiology laboratory of the Faculty of Fez, using Stata software, version 11.0. Descriptive statisticspercentages, mean and standard deviation (SD) - were used to assess patients' characteristics. Student and chi-squared tests were applied to determine factors associated with treatment default, significance was attributed to a probability of $P<0.05$. All variables with a $P$-value $<0.20$ in univariate analysis were included in a conditional logistic regression model, to assess the association between risk factors and treatment compliance, adjusting for potential confounding factors. Variables for the final model were selected using backward elimination.

\section{Results}

The mean age of the 320 patients was 33.0 (SD 12.2) years. A great majority were males (80.6\%) (Table 1). A quarter of participants were illiterate, and four-fifths earned less than 2000 dirham (dh) per month. A little less than 10\% of participants had health insurance. In total, $27.6 \%$ of participants were current smokers and $8.1 \%$ alcohol users.

Concerning the disease, 277 (88.5\%) were new TB cases, and 224 (71.3\%) were pulmonary TB cases. The mean time to get to the TCU was 16.9 (SD 8.9) minutes; $88.8 \%(n=$ 284) of participants went by foot and $9.4 \%(n=30)$ used a taxi. The main characteristics of the study group are shown in Table 1.

Figure 1 presents the knowledge of the study sample about the causes of TB. Several answers were possible. Most participants (31.2\%) considered cold to be the cause of TB, followed by a microbe (27.8\%), while $19.8 \%$ were unable to define a cause for TB. Tobacco smoking (15.6\%), alcohol (2.4\%) and dust or dirt (2.4\%) were also considered

\begin{tabular}{|c|c|c|}
\hline \multicolumn{3}{|c|}{$\begin{array}{l}\text { Table } 1 \text { Demographic and clinical characteristics of the total study group of } \\
\text { tuberculosis (TB) patients }(n=320)\end{array}$} \\
\hline Variable & No. & $\%$ \\
\hline \multicolumn{3}{|l|}{ Sex } \\
\hline Male & 258 & 80.6 \\
\hline Female & 62 & 19.4 \\
\hline \multicolumn{3}{|l|}{ Marital status } \\
\hline Married & 136 & 42.9 \\
\hline Single & 170 & 53.6 \\
\hline Widowed or divorced & 11 & 3.5 \\
\hline \multicolumn{3}{|l|}{ Educational level } \\
\hline Illiterate & 82 & 26.8 \\
\hline Primary education & 127 & 41.5 \\
\hline Secondary education & 82 & 26.8 \\
\hline University & 15 & 4.9 \\
\hline \multicolumn{3}{|l|}{ Employment status } \\
\hline Housewife & 30 & 9.4 \\
\hline Unemployed & 72 & 22.5 \\
\hline Student & 21 & 6.6 \\
\hline Permanent employment & 109 & 34.1 \\
\hline Occasional employment & 84 & 26.3 \\
\hline Retired & 4 & 1.3 \\
\hline \multicolumn{3}{|l|}{ Monthly income (dh) } \\
\hline$<1000$ & 83 & 25.9 \\
\hline $1000-2000$ & 180 & 56.3 \\
\hline $2000-4000$ & 43 & 13.4 \\
\hline$>4000$ & 14 & 4.4 \\
\hline \multicolumn{3}{|l|}{ Health insurance } \\
\hline Yes & 30 & 9.8 \\
\hline No & 275 & 90.2 \\
\hline \multicolumn{3}{|l|}{ TB treatment defaulter } \\
\hline Yes & 108 & 33.8 \\
\hline No & 212 & 66.3 \\
\hline \multicolumn{3}{|l|}{ TB case status } \\
\hline New & 277 & 88.5 \\
\hline Relapsed & 36 & 11.5 \\
\hline \multicolumn{3}{|l|}{ TB location } \\
\hline Pulmonary & 224 & 71.3 \\
\hline Extrapulmonary & 90 & 28.7 \\
\hline
\end{tabular}

$d h=$ Moroccan dirham.

causes. Other causes mentioned were: social conditions/poverty $(n=6)$, waterpipe/hashish/drugs, contact $(n=$ $3)$, water/shower $(n=3)$, stress $(n=2)$, dairy products $(n=2)$, air $(n=1)$, angina $(n=1)$, paint $(n=1)$, tin cans $(n=1)$, milk $(n=1)$, virus $(n=1)$ and diabetes $(n=1)$.
The main reason for defaulting according to the 108 defaulters was the feeling of being cured (82, $75,9 \%)$, followed by the treatment being too long $(42,38,9 \%)$, the lack of overall time $(26,24.1 \%)$ and the lack of knowledge about the benefits of finishing the treatment $(25,23,1 \%)$ 


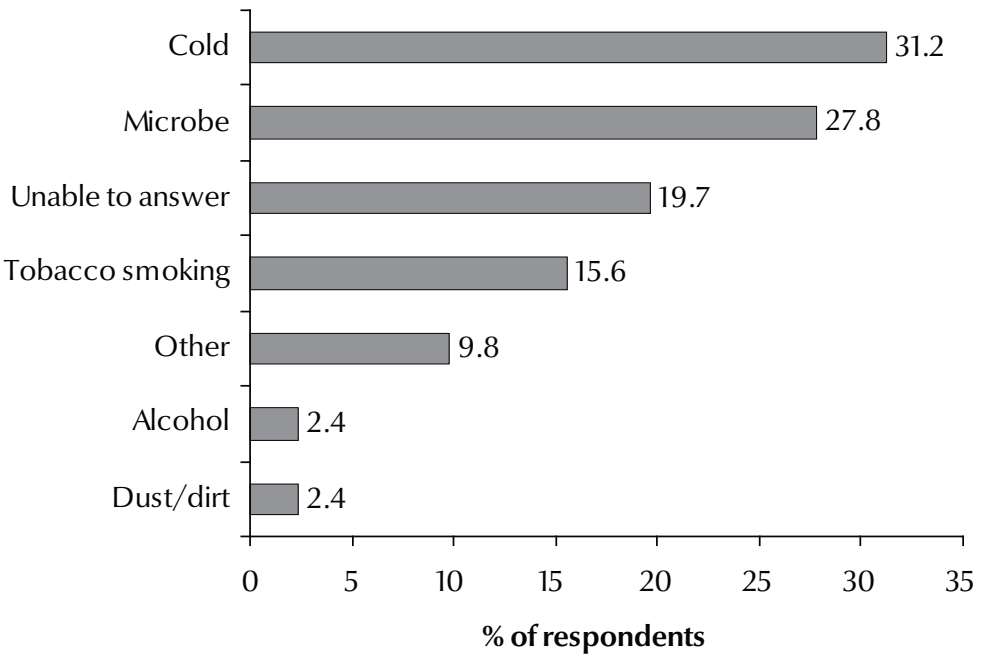

Figure 1 General knowledge about the causes of tuberculosis among the total study group of tuberculosis patients $(n=320)$

(several answers were possible for each patient)

Table 2 describes the characteristics of the defaulters and non-defaulters and risk factors for defaulting after univariate analysis. Significant factors for defaulting were: being a retreatment case, monthly income $<2000 \mathrm{dh}$, being a current smoker, being an alcohol user and perception of having had little or no explanation about the disease $(P \leq 0.05)$.

Table 3 reports the risk factors for TB treatment default from the final model of conditional logistic regression, using a backward stepwise procedure. Significant factors for TB treatment default after adjusting for confounders were: being a relapsed case ( $\mathrm{aOR}$ $=4.49 ; 95 \%$ CI: $1.87-10.8)$, being a current smoker $(\mathrm{aOR}=2.10 ; 95 \% \mathrm{CI}$ : $1.07-4.14)$ or alcohol user $(\mathrm{aOR}=$ 2.92; 95\% CI: 1.04-8.19), taking more than 30 minutes to get to the health centre $(\mathrm{aOR}=3.34 ; 95 \% \mathrm{CI}: 1.06-10.5)$ and perception of having had little or no explanation about the disease $(\mathrm{aOR}=$ 2.87; 95\% CI: 1.53-5.36).

\section{Discussion}

$\mathrm{TB}$ is a main contributor to the global burden of diseases, one of the top 10 causes of death in the world [13]. The existing treatment takes many months and many patients fail to complete the course of drugs prescribed. To determine risk factors for TB treatment default, this research studied several structural, health service and personal factors. In addition, questions were asked about general knowledge of TB and general satisfaction with the care provided and explored patients' subjective reasons for defaulting from $\mathrm{TB}$ treatment. To the best of our knowledge, this study was the first to explore reasons for defaulting from TB treatment in Morocco, and enables us to extract valuable information to improve the effectiveness of management of $\mathrm{TB}$ patients.

The exploration of general knowledge about TB showed a lack of understanding of the disease. Indeed, a majority of participants reported cold as the main cause for their disease, and answers varied widely, ranging from tobacco to dust. Only a little over $25 \%$ were able to attribute TB to a microbe, despite information they should have received in the patient-provider interaction. Also, patients did not seem to know enough about the treatment itself, since defaulters' main reason for defaulting was the feeling of being cured.
These results suggest a lack of quality communication between the health workers and the patients. It seems that modifications in TB care need to be implemented in order to improve communication between health care providers and patients, particularly since several other studies have reported the effectiveness of higher quality communication between patients and health workers in improving treatment adherence and treatment completion $[14,15]$.

Our study suggests that relapsed cases of TB were more at risk of defaulting than new cases. The study of a cohort of retreatment cases in Morocco suggested similar results, with high levels of default from retreatment cases of TB (25\%) [7]. In Turkey, having a previous treatment history for $\mathrm{TB}$ was found after multivariate logistic regression to be the only risk factor for $\mathrm{TB}$ treatment non-adherence [16]. Such results emphasize the need for different management strategies according to the individual starting a new treatment regimen [17], since it is likely that patients who are being retreated for TB are less confident in the drugs and the health care workers, having already been through the process at least once. Also, retreatment cases need to be particularly well-managed because their outcome is often poor, with success rates among relapsed cases lower than among new smear-positive cases, and higher rates of failure and death [6].

Addictive behaviours such as alcohol use and cigarette smoking have been reported in the literature as associated with treatment default. A retrospective cohort study in Russia identified alcohol use during therapy as a predictor of non-adherence $(\mathrm{OR}=6.35 ; 95 \% \mathrm{CI}$ : 2.27-17.8) [18]. Concerning tobacco, many studies have shown associations between tobacco use and failure to complete the treatment. In Sri Lanka, a study of 205 defaulters in $892 \mathrm{~TB}$ cases showed regular smokers to be 1.9 more likely to default than patients who did not smoke regularly [19]. In Malaysia, 


\begin{tabular}{|c|c|c|c|c|c|}
\hline \multirow[t]{2}{*}{ Risk factor } & \multicolumn{2}{|c|}{$\begin{array}{l}\text { Defaulters } \\
(n=108)^{\mathrm{a}}\end{array}$} & \multicolumn{2}{|c|}{$\begin{array}{l}\text { Non-defaulters } \\
\quad(n=212)^{\mathrm{a}}\end{array}$} & \multirow[t]{2}{*}{$P$-value } \\
\hline & No. & $\%$ & No. & $\%$ & \\
\hline \multicolumn{6}{|l|}{ Sex } \\
\hline Male & 88 & 81.5 & 170 & 80.2 & \multirow[t]{2}{*}{0.88} \\
\hline Female & 20 & 18.5 & 42 & 19.8 & \\
\hline \multicolumn{6}{|l|}{ Age (years) } \\
\hline$\leq 30$ & 58 & 53.7 & 107 & 50.5 & \multirow[t]{2}{*}{0.64} \\
\hline$>30$ & 50 & 46.3 & 105 & 49.5 & \\
\hline \multicolumn{6}{|l|}{ TB case status } \\
\hline Relapsed & 22 & 20.7 & 14 & 6.8 & \multirow[t]{2}{*}{$<0.001$} \\
\hline New & 84 & 79.2 & 193 & 93.2 & \\
\hline \multicolumn{6}{|l|}{ TB location } \\
\hline Pulmonary & 82 & 76.6 & 142 & 68.6 & \multirow[t]{2}{*}{0.14} \\
\hline Extrapulmonary & 25 & 23.4 & 65 & 31.4 & \\
\hline \multicolumn{6}{|l|}{ Marital status } \\
\hline Married & 44 & 40.7 & 92 & 44.0 & \multirow[t]{2}{*}{0.63} \\
\hline Other & 64 & 59.3 & 117 & 56.0 & \\
\hline \multicolumn{6}{|l|}{ Housing conditions ${ }^{b}$} \\
\hline Comfortable & 7 & 6.5 & 12 & 5.7 & \multirow[t]{2}{*}{0.80} \\
\hline Medium or precarious & 100 & 93.5 & 198 & 94.3 & \\
\hline \multicolumn{6}{|l|}{ Educational level } \\
\hline Illiterate & 33 & 31.4 & 49 & 24.4 & \multirow[t]{2}{*}{0.19} \\
\hline Other & 72 & 68.6 & 152 & 75.6 & \\
\hline \multicolumn{6}{|l|}{ Employment category } \\
\hline Active & 59 & 54.6 & 127 & 59.9 & \multirow[t]{2}{*}{0.40} \\
\hline Non-active & 49 & 45.4 & 85 & 40.1 & \\
\hline \multicolumn{6}{|l|}{ Monthly income (dh) } \\
\hline$\leq 2000$ & 98 & 90.7 & 165 & 77.8 & \multirow[t]{2}{*}{0.004} \\
\hline$>2000$ & 10 & 9.3 & 47 & 22.2 & \\
\hline \multicolumn{6}{|l|}{ Tobacco use } \\
\hline Current smoker & 43 & 39.8 & 45 & 21.3 & \multirow[t]{2}{*}{$<0.001$} \\
\hline Ex- or non-smoker & 65 & 60.2 & 166 & 78.7 & \\
\hline Alcohol use & & & & & \\
\hline User & 17 & 15.7 & 9 & 4.2 & $<0.001$ \\
\hline Non-user & 91 & 84.3 & 203 & 95.8 & \\
\hline Time to get to treatment $\mathrm{c}$ & & & & & \\
\hline$\leq 30 \mathrm{~min}$ & 97 & 89.8 & 201 & 95.3 & 0.06 \\
\hline$>30 \mathrm{~min}$ & 11 & 10.2 & 10 & 4.7 & \\
\hline Received explanation abo & & & & & \\
\hline Little or none & 37 & 34.3 & 33 & 15.7 & $<0.001$ \\
\hline Sufficient & 71 & 65.7 & 177 & 84.3 & \\
\hline Experienced side-effects of & & & & & \\
\hline Yes & 27 & 26.0 & 46 & 21.8 & 0.48 \\
\hline No & 77 & 65.7 & 165 & 78.2 & \\
\hline
\end{tabular}

a Percentages in each group are based on total responding to each item.

${ }^{b}$ Researcher's judgement.

All variables with P-value $<0.20$ were included in a conditional logistic regression analysis.

$d h=($ Moroccan $)$ dirham . 


\begin{tabular}{lcc}
\hline $\begin{array}{l}\text { Table } 3 \text { Risk factors for default from tuberculosis treatment in the final model of } \\
\text { the multivariate conditional logistic regression }\end{array}$ \\
\begin{tabular}{lcc}
\hline Risk factor & OR $(95 \% \mathrm{Cl})$ & $\boldsymbol{P}$-value \\
Relapsed case & $4.49(1.87-10.8)$ & $<0.001$ \\
Current smoker & $2.10(1.07-4.14)$ & 0.03 \\
Alcohol user & $2.92(1.04-8.19)$ & 0.04 \\
$>30$ min. to treatment centre & $3.34(1.06-10.5)$ & 0.04 \\
Received insufficient explanation & & $<0.001$ \\
about disease & $2.87(1.53-5.36)$ & \\
\hline
\end{tabular}
\end{tabular}

$O R=$ odds ratio; $C l=$ confidence interval .

ever smokers had increased likelihood of treatment default (adjusted OR = 3.24) [20]. These findings are important to consider when treating a new $\mathrm{TB}$ patient. In our study tobacco and alcohol use were associated with a higher risk of default, and these have also been reported to worsen TB outcomes $[21,22]$. It seems essential to search for and include these factors in the management of all new TB patients, as alcohol and tobacco use are personal risk factors that can be dealt with.

Access to the TCU was also an issue in our study. When the time needed to get to the TCU exceeded $30 \mathrm{~min}$ utes, patients were 3.34 times (95\% CI: $1.06-10.5)$ more likely to default from treatment than patients who were less than 30 minutes away. Similar results can be found in the literature $[23,24]$, whether taking into account the distance or the time to get to the health centre. Cost of transport was not an issue in this study, particularly since almost $90 \%$ of patients were at a walking distance to the health centre. This high number of patients who did not need taxis or public transport to go to the health centre suggests a good distribution of health centres in the town of Fez. In this context, it is possible that loss of availability for work and therefore time for earning money was the most important factor, particularly if patients underestimate the importance of treatment completion.

This study is unique as it was the first in Morocco to explore subjective factors that could be linked to treatment default in addition to objective sociodemographic factors. However, some limitations need to be pointed out. Interviews were carried out by the nurses working in the TCUs. Consequently, questions that tried to evaluate relations and interaction with the health care workers might have led to interview bias, with nurses possibly leading questions and respondents wishing to evade or lie to some questions. Similarly, all questions relating to monthly earnings or addictive substance use are subject to response bias, particularly in the context of Moroccan society where alcohol drinking is uncommon in general and smoking very uncommon among women and thus participants are likely to under-report their consumption. However, such concerns are true for the whole study population, whether defaulters or non-defaulter, thus limiting the bias. In addition, untruthful answers were likely to have been limited by the thorough explanations given by the nurses before the interviews and the complete anonymity of questionnaires. Another limitation that needs to be acknowledged is the retrospective nature of the study. Some participants were treated more than 2 years ago and this might have been a source of recall bias. However, some information lost due to recall was completed to a certain extent by the review of the medical records.

Despite the above considerations, the study design enabled us to quickly obtain information on defaulters in $\mathrm{Fez}$, and to identify some reasons for defaulting. With $75.7 \%$ of defaulters reporting the feeling of being cured as the main reason for default, there is an evident lack of quality communication between the health care teams and the patients, and a qualitative follow-up study in which both patients and health workers are interviewed might provide useful insights on the attitudes and practices in the TCUs. In addition to a perception that they had received insufficient explanation about the disease, patients at risk of treatment default in the urban area of Fez were more likely to be relapsed cases, alcohol users or current smokers and needed more than 30 minutes to get to the TCUs. The results suggest that modifications should be introduced in TB care in Morocco, particularly since realistic measures can be implemented to remove barriers and improve compliance. Reducing the number of defaulters is possible through realistic measures such as reinforcing quality communication between patients and providers, implementing programmes to treat addictive behaviours and increasing accessibility to the TCUs. Such measures are likely to increase the therapeutic success rate, impacting on global disease burden attributable to TB in Morocco.

Competing interests: None declared.

\section{References}

1. India TB. 2009. Revised National Tuberculosis Control Programme (RNTCP) status report. New Delhi, India, Ministry of Health and Family Welfare, Central TB Division, 2009.
2. TB Unit of the WHO Regional Office for the Eastern Mediterranean. Country profile 2008-09: Morocco. Geneva, World Health Organization, 2009. 
3. Santé en chiffres 2009. Rabat, Ministry of Health, Directorate of Planning and Financial Resources, Division of Planning and Studies, 2009 [in French].

4. Progress report on achievement of the Millennium Development Goals. Cairo, World Health Organization Regional Office for the Eastern Mediterranean, 2010 (EM/RC57/INF.DOC.3).

5. Verver $\mathrm{S}$ et al. Rate of reinfection tuberculosis after successful treatment is higher than rate of new tuberculosis. American Journal of Respiratory and Critical Care Medicine, 2005, 171:1430-1435.

6. Ottmani SE et al. Results of cohort analysis by category of tuberculosis retreatment cases in Morocco from 1996 to 2003. International Journal of Tuberculosis and Lung Disease, 2006, 10:1367-1372.

7. Dooley KE et al. Risk factors for tuberculosis treatment failure, default, or relapse and outcomes of retreatment in Morocco. BMC Public Health, 2011, 11:140.

8. Volmink J, Garner P. Directly observed therapy for treating tuberculosis. Cochrane Database of Systematic Reviews, 2007, 4:CD003343.

9. Vree $\mathrm{M}$ et al. Mortality and failure among tuberculosis patients who did not complete treatment in Vietnam: a cohort study. BMC Public Health, 2007, 7:134.

10. Kolappan $\mathrm{C}$ et al. Mortality of tuberculosis patients in Chennai, India. Bulletin of the World Health Organization, 2006, 84:555-560.

11. Anti-tuberculosis drug resistance in the world (Report No. 4). The WHO/IUATLD global project on anti-tuberculosis drug resistance surveillance. Geneva, World Health Organization/International Union Against Tuberculosis and Lung Disease, 2008.

12. Treatment of tuberculosis: guidelines for national programmes. Geneva, World Health Organization (WHO/HTM/ TB/2009.420).

13. The top 10 causes of death. Fact sheet No. 370. Geneva, World Health Organization, 2008.

14. Mishra P et al. Adherence is associated with the quality of professional-patient interaction in Directly Observed Treat- ment Short-course, DOTS. Patient Education and Counseling, 2006, 63:29-37.

15. Dick J et al. Changing professional practice in tuberculosis care: an educational intervention. Journal of Advanced Nursing, 2004, 48:434-442.

16. Sevim T et al. Treatment adherence of 717 patients with tuberculosis in a social security system hospital in Istanbul, Turkey. International Journal of Tuberculosis and Lung Disease, 2002, 6:25-31.

17. Zignol $M$ et al. Patients with previously treated tuberculosis no longer neglected. Clinical Infectious Diseases, 2007, 44:61-64.

18. 18. Gelmanova IY et al. Barriers to successful tuberculosis treatment in Tomsk, Russian Federation: non-adherence, default and the acquisition of multidrug resistance. Bulletin of the World Health Organization, 2007, 85:703-711.

19. Pinidiyapathirage J, Senaratne W, Wickremasinghe R. Prevalence and predictors of default with tuberculosis treatment in Sri Lanka. Southeast Asian Journal of Tropical Medicine and Public Health, 2008, 39:1076-1082.

20. Dujaili JA et al. Outcomes of tuberculosis treatment: a retrospective cohort analysis of smoking versus non-smoking patients in Penang, Malaysia. Journal of Public Health, 2011, 19:183-189.

21. Chiang CY, Slama K, Enarson DA. Associations between tobacco and tuberculosis. International Journal of Tuberculosis and Lung Disease, 2007, 11:258-262.

22. Lönnroth $\mathrm{K}$ et al. Alcohol use as a risk factor for tuberculosis-a systematic review. BMC Public Health, 2008, 8:289.

23. Comolet TM, Rakotomalala R, Rajaonarioa H. Factors determining compliance with tuberculosis treatment in an urban environment, Tamatave, Madagascar. International Journal of Tuberculosis and Lung Disease, 1998, 2:891-897.

24. Brasil PE, Braga JU. Meta-analysis of factors related to health services that predict treatment default by tuberculosis patients. Cadernos de Saude Publica, 2008, 24(Suppl. 4):s485s502. 